\title{
How to Write Scientific Journals of the Highest Standards
}

Type of article: conference Abstract

\author{
Mehrdad Jalalian \\ Mehr Publishing Group \\ drjalalian@yahoo.com
}

\begin{abstract}
One of the requirements of a Ph.D. or Master is to write traditional and systematic reviews, critiques, letters to editors (LTE), case reports or case studies, at least one original article, and sometimes a meta-analysis, all with proficiency and inspiration. This presentation focuses on the ideas from research to publication, i.e., how to depict a distinct image in our mind in order to convert our research into various types of academic papers. Also, this presentation provides a general approach and some key points for writing and successfully publishing journal papers. The presentation will also cover some publication ethics guidelines, ethics of reporting questionnaire-based research, authorship criteria, plagiarism detection and how to avoid plagiarism, duplicate publication, and salami publication.
\end{abstract}

Keywords: Scientific writing, journal paper, original articles, case report, ethics.

\section{Declaration of conflicts}

This article was presented at ICHSMT'16 as a key notes.

\section{Authors' biography}

Dr. Mehrdad Jalalian is editor-in-chief of Electronic Physician Journal. He is also a researcher on publication ethics, scientific writing, and scholarly publishing. Website: http://www.ephysician.ir, Email: drjalalian@yahoo.com

\section{References}

\section{No reference}

